\title{
Palliative and End of Life Care in Undergraduate Medical Education: A Survey of New Zealand Medical Schools
}

Lis Heath ( $\square$ lis.heath@otago.ac.nz)

University of Otago

Richard Egan

University of Otago

Ella losua

University of Otago

Robert Walker

University of Otago

Jean Ross

Otago Polytechnic

Rod MacLeod

University of Auckland

\section{Research Article}

Keywords: Palliative, end of life care, education, undergraduate, curriculum, medical students

Posted Date: December 8th, 2021

DOI: https://doi.org/10.21203/rs.3.rs-1112411/v1

License: (9) (i) This work is licensed under a Creative Commons Attribution 4.0 International License.

Read Full License 


\section{Abstract}

Background: In New Zealand, 34\% of deaths occur in the hospital setting where junior doctors are at the frontline of patient care. The death rate in New Zealand is expected to double by 2068 due to the aging population, but many studies report that graduates feel unprepared to care for people near the end of life and find this to be one of the most stressful parts of their work. International guidelines recommend that palliative and end of life care should be a mandatory component of undergraduate medical education, yet teaching varies widely and remains optional in many countries. Little is known about how medical students in New Zealand learn about this important area of clinical practice. The purpose of this study was to investigate the organisation, structure and provision of formal teaching, assessment and clinical learning opportunities in palliative and end of life care for undergraduate medical students in New Zealand.

Methods: Quantitative descriptive, cross-sectional survey of module conveners in New Zealand medical schools.

Results: Palliative and end of life care is included in undergraduate teaching in all medical schools. However, there are gaps in content, minimal formal assessment and limited contact with specialist palliative care services. Lack of teaching staff and pressure on curriculum time are the main barriers to further curriculum development.

Conclusions: This article reports the findings of the first national survey of formal teaching, assessment and clinical learning opportunities in palliative and end of life care in undergraduate medical education in New Zealand. There has been significant progress towards integrating this content into the curriculum, although further development is needed to address barriers and maximise learning opportunities to ensure graduates are as well prepared as possible.

\section{Background}

Palliative care and end of life care (PEOLC) is widely regarded as an important component of undergraduate medical education. However, this subject remains optional in many areas, which fails to prepare doctors for the inevitable reality that patients will die while in their care. The COVID-19 pandemic brought this issue into sharp relief as healthcare providers around the world have struggled to meet demand as hospitals became overwhelmed with sick and dying patients. While New Zealand (NZ) has fared better than most countries during the pandemic, the death rate from life-limiting diseases is expected to double by 2068 with most deaths occurring in people aged $>85$ years. This increase will be reflected across all healthcare settings, with a $51 \%$ rise in palliative care need by 2038 [1]. These statistics reflect a global challenge in healthcare that is, unfortunately, not amenable to a vaccine.

Approximately one-third of deaths in NZ occur in acute care hospitals where at least $20 \%$ of inpatients meet the Gold Standards criteria for palliative care [2]. Most graduates complete their first two years of clinical practice in hospital settings so they are likely to encounter people with palliative and end of life 
care needs on a regular basis. In fact, a study from the United Kingdom (UK) which investigated medical students' attitudes towards palliative care, reported that junior doctors care for approximately 40 people who die, and a further 120 people who are close to the end of life, in their first year after qualifying [3]. Given the NZ statistics previously mentioned, it seems likely that NZ graduates may experience a similar reality.

PEOLC has not traditionally been included in undergraduate teaching due to an emphasis on curative medicine and the availability of treatments and investigations which seek to prolong life at any cost. Unfortunately, this denies patients and their whānau (family) the care and support they need at a time when quality of life should be a priority. In the absence of such training, newly qualified doctors are likely to enter clinical practice without the necessary knowledge, skills or attitudes to provide basic palliative care. However, attitudes are changing and this content is now being integrated into undergraduate curricula around the world, which is a fundamental step towards improving awareness, workforce capacity and increasing access to primary (non-specialist) palliative care $[4,5]$.

The very nature of caring for people with life-limiting conditions is inherently challenging, and studies report that newly qualified doctors find caring for people toward the end of life stressful and emotionally distressing $[3,6,7]$. This is perhaps, not surprising. However, deficiencies in undergraduate education such as lack of meaningful contact with people who are dying, lack of role modelling by senior physicians, curative oriented health systems and variable teaching, fails to prepare students for one of the most challenging aspects of their work. These issues ultimately compromise patient care and increase graduates' anxiety at a critical point in their professional development $[6,8,9]$. Negative personal attitudes and beliefs about death and dying may also influence graduates' willingness to care for people at the end of life [10], although education has been shown to be effective in addressing these issues [11, 12]. In the absence of such education, graduates must rely on their intuition and guidance from colleagues, which may be neither available nor appropriate if their colleagues have not received formal training in palliative and end of life care (PEOLC).

In 2014, a declaration by the World Health Assembly stated that "palliative care should be integrated as a routine component of undergraduate medical education" to improve access to primary palliative care [13]. International recommendations suggest teaching should be based on nationally agreed and developmentally appropriate competencies with dedicated clinical exposure, reflection and discussion about challenging cases, assessment and multidisciplinary input $[14,15]$. A variety of international guidelines and competency frameworks have since been developed to support this work. For example, the EDUPALL curriculum, based on recommendations from the European Association for Palliative Care (EAPC) (edupall.eu); Educating Future Physicians in Palliative and End of Life Care curriculum in Canada (EFPPEC); Palliative Care for Undergraduates sponsored by the Australian government (pcc4u.org); All Ireland Institute of Hospice Palliative Care competence framework (http://aiihpc.org/), and the Northern Ireland Health and Social Care Palliative and End of Life Care Competency Assessment Tool. 
Early efforts to include PEOLC in undergraduate curricula tended to be optional, fragmented and lacked coordination [9]. However, there is now greater consistency in curricular offerings [16]. Canada, the UK, Austria, Belgium, Estonia, Switzerland, Israel, Luxembourg, Moldova, Belgium, France, and Germany now include PEOLC as a mandatory component of undergraduate medical education. A further 13 European countries teach PEOLC combined with another medical specialty, e.g. palliative care and oncology [1719]. Unfortunately, few European countries offer more than 20 hours of formal palliative care teaching or mandatory clinical experience in palliative care. In the US, medical schools are not required to teach palliative care competencies. While a 2014 review reported that palliative care is included in most medical schools' curricula, teaching varies widely and is underdeveloped [15]. Similarly, a 2014 report described PEOLC teaching in Australian medical schools as variable, fragmented and disjointed. Despite global efforts to increase undergraduate PEOLC education, overcrowded curricula, insufficient time, lack of faculty expertise and leadership, and a lack of funding and assessment, thwart the ability to do so [15, 20-22]. Despite that, student evaluations show they value this teaching, consider it relevant to general clinical practice, and feel it improves confidence in their ability to care for people near the end of life [23]. Palliative care teaching has also been shown to foster holistic patient-centred care and professional development [24].

New Zealand is currently ranked third on the global Quality of Death Index, which rates the provision of palliative care worldwide based on income as a predictor of the availability and quality of services [25]. Specialist palliative care services are well established in urban centres throughout NZ, although people in rural and remote communities often have to travel long distances to access this care. Therefore, up to $80 \%$ of palliative care is provided by health professionals who may not have had any formal training in palliative care [1], supported by specialist palliative care services where available, and the national guidelines: Te Ara Whakapiri - Principles and Guidance for The Last Days of Life [26]. However, there is an impending shortage of palliative medicine specialists, and district health boards report difficulty recruiting and retaining suitably qualified staff, which has led to inequities in access for patients and families needing care and for healthcare providers seeking support [1]. These issues were highlighted in the NZ Ministry of Health Palliative Care Action Plan [27], which prioritised workforce development by "supporting work to modify undergraduate education and training to provide the minimum knowledge and skills related to primary palliative care" (p.23). This statement provides a clear mandate for medical schools to ensure PEOLC is comprehensively addressed in the undergraduate curriculum to ensure graduates have the necessary skills to provide equitable access to primary palliative care across all healthcare settings and geographic locations. Unfortunately, the shortage of palliative medicine specialists required to teach this material may undermine the ability to deliver on this priority.

There are two accredited providers of undergraduate medical education in NZ (the University of Otago and the University of Auckland), with a combined annual intake of around 550 students. Students gain entry through a highly competitive one-year health sciences course, or the alternate pathway for those with a prior degree, followed by two years of pre-clinical education with some early clinical exposure, and three years of clinical training in hospital and community settings. The sixth and final year is spent working as a Trainee Intern. Graduates obtain provisional registration and are awarded with a Bachelor of 
Medicine and Bachelor of Surgery degree (MBChB). They then undertake a further two years of prevocational training as a House Officer (PGY1-2) before being registered as a medical practitioner [28]. Medical students at Otago University complete the first three years of the course in Dunedin, then divide into thirds for years 4-6 in one of three clinical teaching campuses in Dunedin, Christchurch and Wellington. Students at Auckland University follow a similar pathway with clinical attachments in hospital and community settings throughout Auckland and regional centres in the North Island.

While MBChB programmes are accredited by the Australian Medical Council, the Medical Council of New Zealand [29] sets the standards for medical practice, which includes care at the end of life. Learning outcomes and objectives in PEOLC are included in each universities' curriculum documents to influence curriculum planning, development and delivery. There are no academic professors of palliative medicine at either of NZ's medical schools and only a handful of academic appointments to teach palliative care.

In 1997, a palliative care curriculum for undergraduate medical students was introduced by the Australian \& New Zealand Society for Palliative Medicine (ANZSPM) and accepted by the Deans of all medical schools in Australia and NZ but unfortunately, little change eventuated. However, collaboration between Otago and Auckland universities to address deficiencies in PEOLC teaching has since resulted in the development of a national undergraduate PEOLC curriculum and implementation framework, which incorporates the previous work done by ANZSPM. It is against this background that the first national survey of NZ medical schools was undertaken to provide a baseline for further development.

\section{Methods}

This study used quantitative descriptive methodology with an anonymised, national, online crosssectional survey of medical schools to obtain information about the organisation, structure and provision of formal teaching, assessment and clinical learning opportunities in PEOLC in undergraduate medical education in New Zealand. The study was approved by the University of Otago Human Ethics Committee on 31 January 2019 (ref \#: 19/009).

The online survey was adapted (with permission) from a UK survey of medical schools [18], initially developed by Field and Wee [30], and delivered using the Qualtrics survey platform. Data collection occurred between March-June 2019. Survey participants were those responsible for coordinating teaching in PEOLC (conveners). Conveners were asked to select from a range of responses to questions about the organisation, leadership, curriculum content, teaching methods, clinical exposure to palliative care providers, and formal assessment in PEOLC. Space for free text comments allowed conveners to provide more detail with an assurance that all information would be reported anonymously. The survey was piloted by a group of educators and an e-learning facilitator before being distributed.

Each convener was contacted by email which contained a link to the survey. The survey was front-loaded with the information sheet and consent form, and then directed participants to the survey, which took approximately 15 minutes to complete. Three reminders were sent at ten-day intervals before closing the survey. An initial report was obtained through the Qualtrics survey platform, and STATA software version 
15.0 was used to calculate the descriptive statistics. Where more than one response was received from the same school, results were compared, collated and clarified with the respondent if necessary.

\section{Results}

Replies were received from all four conveners from the medical schools based in Dunedin and Auckland, and the two University of Otago teaching campuses for Year 4-6 students in Christchurch and Wellington.

\section{Organisation and Leadership}

An identified convener is responsible for coordinating PEOLC teaching on each campus. All conveners reported that PEOLC is vertically integrated throughout the undergraduate curriculum beginning in year 2 . A total $>40$ hours of formal teaching from years 2- 6 was reported by three conveners (not including clinical attachments), and one convener reported 21-30 hours. Programme evaluation reflects a commitment to ongoing improvement and all conveners reported that PEOLC teaching is routinely evaluated. However, formal assessment of student learning in PEOLC was only reported by three conveners. All conveners receive financial remuneration for coordinating PEOLC education as part of their wider roles and responsiblities, have advanced training in palliative care and are clinically active in the specialty. The majority of teaching is provided by medical and nursing staff from either a palliative care or primary care background, with additional input from other disciplines such as counsellors, social workers, spiritual care coordinators and academic lecturers.

\section{Teaching Methods}

All conveners reported using lectures, tutorials and reflective activities for PEOLC teaching. Supervised clinical experience with palliative care providers is available on all campuses, albeit for a minimal time. Case discussions and DVDs, films and podcasts are used on three campuses. Interviews or presentations with patients and informal carers are used on two

campuses, and one convener reported the use of E-learning resources.

\section{Teaching content and perceived adequacy}

Table 1 presents the range of topics included in PEOLC teaching at the time of the survey. Three conveners reported that approximately half of these subjects are either adequately or comprehensively addressed. Subjects taught only 'a little' or 'not covered' at all included cultural and religious issues, palliative care emergencies, assessment and management of other symptoms, confusion and constipation. Only one convener reported that these subjects were 'adequately' or 'comprehensively' addressed in their curriculum. Communicating in high stakes situations was addressed 'a little' on three campuses, and only two conveners reported that spirituality, nutrition and hydration, last days of life, personal coping, and loss, grief \& bereavement were 'adequately' or 'comprehensively' addressed. Teaching about ethical issues is covered to varying extents ranging from 'a little' to 'comprehensive' at 
three schools. Euthanasia and assisted dying will need to be carefully reviewed with the introduction of legislation in November 2021 that legalised assisted dying. 
Table 1

Teaching content and perceived adequacy

\begin{tabular}{|c|c|c|c|c|}
\hline & $\begin{array}{l}\text { "Not } \\
\text { covered" } \\
\text { n (\%) }\end{array}$ & $\begin{array}{l}\text { "A } \\
\text { little" } \\
n(\%)\end{array}$ & $\begin{array}{l}\text { "Adequate" } \\
\text { n (\%) }\end{array}$ & $\begin{array}{l}\text { "Comprehensive" } \\
\text { n (\%) }\end{array}$ \\
\hline Definition \& philosophy of palliative care & 0 & $\begin{array}{l}1 \\
(25)\end{array}$ & 0 & $3(75)$ \\
\hline Attitudes towards death \& dying & 0 & 0 & $1(25)$ & $3(75)$ \\
\hline $\begin{array}{l}\text { Social contexts of dying e.g. home, rest } \\
\text { home, hospital, hospice }\end{array}$ & 0 & $1(25)$ & 2(50) & $1(25)$ \\
\hline Assessment \& management of pain & 0 & 0 & $1(25)$ & $3(75)$ \\
\hline $\begin{array}{l}\text { Assessment \& management of nausea \& } \\
\text { vomiting }\end{array}$ & 0 & $1(25)$ & 2(50) & $1(25)$ \\
\hline $\begin{array}{l}\text { Assessment \& management of } \\
\text { breathlessness }\end{array}$ & 0 & $1(25)$ & $2(50$ & $1(25)$ \\
\hline Assessment \& management of constipation & 0 & $3(75)$ & 0 & $1(25)$ \\
\hline $\begin{array}{l}\text { Assessment \& management of agitation \& } \\
\text { confusion }\end{array}$ & $1(25)$ & $2(50)$ & $1(25)$ & 0 \\
\hline $\begin{array}{l}\text { Assessment \& management of other } \\
\text { symptoms }\end{array}$ & $1(25)$ & $2(50)$ & $1(25)$ & 0 \\
\hline Non-pharmacological symptom management & 0 & $1(25)$ & $3(75)$ & 0 \\
\hline Nutrition \& hydration at the end of life & 0 & $2(50)$ & $2(50$ & 0 \\
\hline Care in the last days of life & 0 & $2(50)$ & $2(50)$ & 0 \\
\hline Palliative care emergencies & $1(25)$ & $2(50)$ & $1(25)$ & 0 \\
\hline Loss, grief \& bereavement & $1(25)$ & $1(25)$ & $1(25)$ & $1(25)$ \\
\hline $\begin{array}{l}\text { Impact of illness on patient \& family/whanau } \\
\text { (e.g. anxiety \& depression) }\end{array}$ & 0 & $1(25)$ & $1(25)$ & $2(50)$ \\
\hline $\begin{array}{l}\text { Spirituality (e.g. the role of spirituality in } \\
\text { healthcare, spiritual distress, hope) }\end{array}$ & $1(25)$ & $1(25)$ & $1(25)$ & $1(25)$ \\
\hline Cultural \& religious issues in end of life care & $1(25)$ & $2(50)$ & $1(25)$ & 0 \\
\hline $\begin{array}{l}\text { Ethical \& legal issues e.g. futility, } \\
\text { withdrawing/withholding treatment, } \\
\text { euthanasia) }\end{array}$ & 0 & $1(25)$ & $2(50)$ & $1(25)$ \\
\hline $\begin{array}{l}\text { Mental capacity, advance directives \& } \\
\text { Enduring Power of Attorney }\end{array}$ & 0 & $1(25)$ & $2(50)$ & $1(25)$ \\
\hline Death certification & 0 & $1(25)$ & $3(75)$ & 0 \\
\hline
\end{tabular}




\begin{tabular}{|lllll|}
\hline & $\begin{array}{l}\text { "Not } \\
\text { covered" } \\
\mathbf{n}(\%)\end{array}$ & $\begin{array}{l}\text { "A } \\
\text { little" } \\
\mathbf{n}(\%)\end{array}$ & $\begin{array}{l}\text { "Adequate" } \\
\mathbf{n}(\%)\end{array}$ & $\begin{array}{l}\text { "Comprehensive" } \\
\mathbf{n}(\%)\end{array}$ \\
\hline $\begin{array}{l}\text { Communicating in high stakes situations } \\
\text { (e.g. goals of care, advance care planning, } \\
\text { DNACPR }\end{array}$ & 0 & $3(75)$ & $1(25)$ & 0 \\
\hline Personal coping strategies & $1(25)$ & $1(25)$ & $1(25)$ & $1(25)$ \\
\hline Reflective practice & $1(25)$ & 0 & 0 & $3(75)$ \\
\hline Interdisciplinary teamwork & $1(25)$ & 0 & $2(50)$ & $1(25)$ \\
\hline $\begin{array}{l}\text { Models of care: curative, palliative, disease- } \\
\text { modifying }\end{array}$ & 0 & $1(25)$ & $1(25)$ & $2(50)$ \\
\hline
\end{tabular}

\section{Clinical contact with palliative care providers}

Table 2 provides an overview of clinical contact with palliative care providers, including general practice and aged care. Second-year students at one university are introduced to palliative care by working in residential aged care facilities as assistant caregivers for up to one week, with additional time for preparation and guided reflection afterwards. Contact with specialist palliative care providers is limited. All conveners reported that students visit a hospice for at least one half-day during their training, and one school offers an optional two-week placement for trainee interns as part of a community attachment. Elective hospice experiences are available for senior students in two locations, although only one student can be accommodated at a time. Experience in hospice day units is limited and depends on whether this service is available in the student's location. There is very little exposure to hospital palliative care services and no opportunities for students to observe palliative care outpatient clinics. Most clinical exposure (outside the hospital setting) occurs in general practice settings where interaction with people with PEOLC needs occurs opportunistically. 
Table 2

Clinical contact with palliative care providers

\begin{tabular}{|lllllll|}
\hline & None & $\begin{array}{l}\text { Up to half } \\
\text { day (\%) }\end{array}$ & $\begin{array}{l}\text { Up to } 1 \\
\text { day(\%) }\end{array}$ & $\begin{array}{l}\text { 1 day to 1 } \\
\text { week (\%) }\end{array}$ & $\begin{array}{l}\text { >1 } \\
\text { week } \\
\text { (\%) }\end{array}$ & $\begin{array}{l}\text { Repeated } \\
\text { activity (\%) }\end{array}$ \\
\hline Hospice IPU & 0 & $3(75)$ & 0 & $1(25)$ & 0 & 0 \\
\hline $\begin{array}{l}\text { Hospice } \\
\text { community team }\end{array}$ & $\begin{array}{l}1 \\
(25)\end{array}$ & $2(50)$ & $1(25)$ & 0 & 0 & 0 \\
\hline Hospice day unit & $\begin{array}{l}3 \\
(75)\end{array}$ & 0 & $1(25)$ & 0 & 0 & 0 \\
\hline $\begin{array}{l}\text { PC outpatient } \\
\text { clinic }\end{array}$ & $\begin{array}{l}4 \\
(100)\end{array}$ & 0 & 0 & 0 & 0 & 0 \\
\hline $\begin{array}{l}\text { Hospital PC } \\
\text { service }\end{array}$ & $\begin{array}{l}2 \\
(50)\end{array}$ & $2(50)$ & 0 & 0 & 0 & 0 \\
\hline $\begin{array}{l}\text { Residential aged } \\
\text { care }\end{array}$ & $\begin{array}{l}3 \\
(75)\end{array}$ & 0 & 0 & $1(25)$ & 0 & 0 \\
\hline $\begin{array}{l}\text { PC patients in GP } \\
\text { setting }\end{array}$ & $\begin{array}{l}1 \\
(25)\end{array}$ & 0 & $2(50)$ & 0 & 0 & $1(25)$ \\
\hline PC elective & $\begin{array}{l}2 \\
(50)\end{array}$ & 0 & 0 & 0 & 2 & 0 \\
\hline
\end{tabular}

PC = Palliative Care GP = General Practice

\section{Assessment}

Formal assessment of learning in PEOLC was carried out on three campuses at the time of the survey. Table 3 shows that multiple-choice questions and reflective essays are the favoured approaches to assessment. Observed Structured Clinical Examinations (OSCE) involving PEOLC scenarios are used for summative assessment on one campus, which includes the use of opioids and explaining palliative care to a patient. Guided reflection following a filmed simulation of a breaking bad news scenario was reported by one convener to assess communication skills. Case presentations of a person with PEOLC needs was reported by one convener, although this only occurs opportunistically. Clinical supervisor feedback was limited to the school that provides a longer hospice attachment, which allows for more informed feedback about student competencies in PEOLC. Observed history and examination of a palliative care patient and extended multiple-choice questions were not reported at all.

Table 3: Assessment 


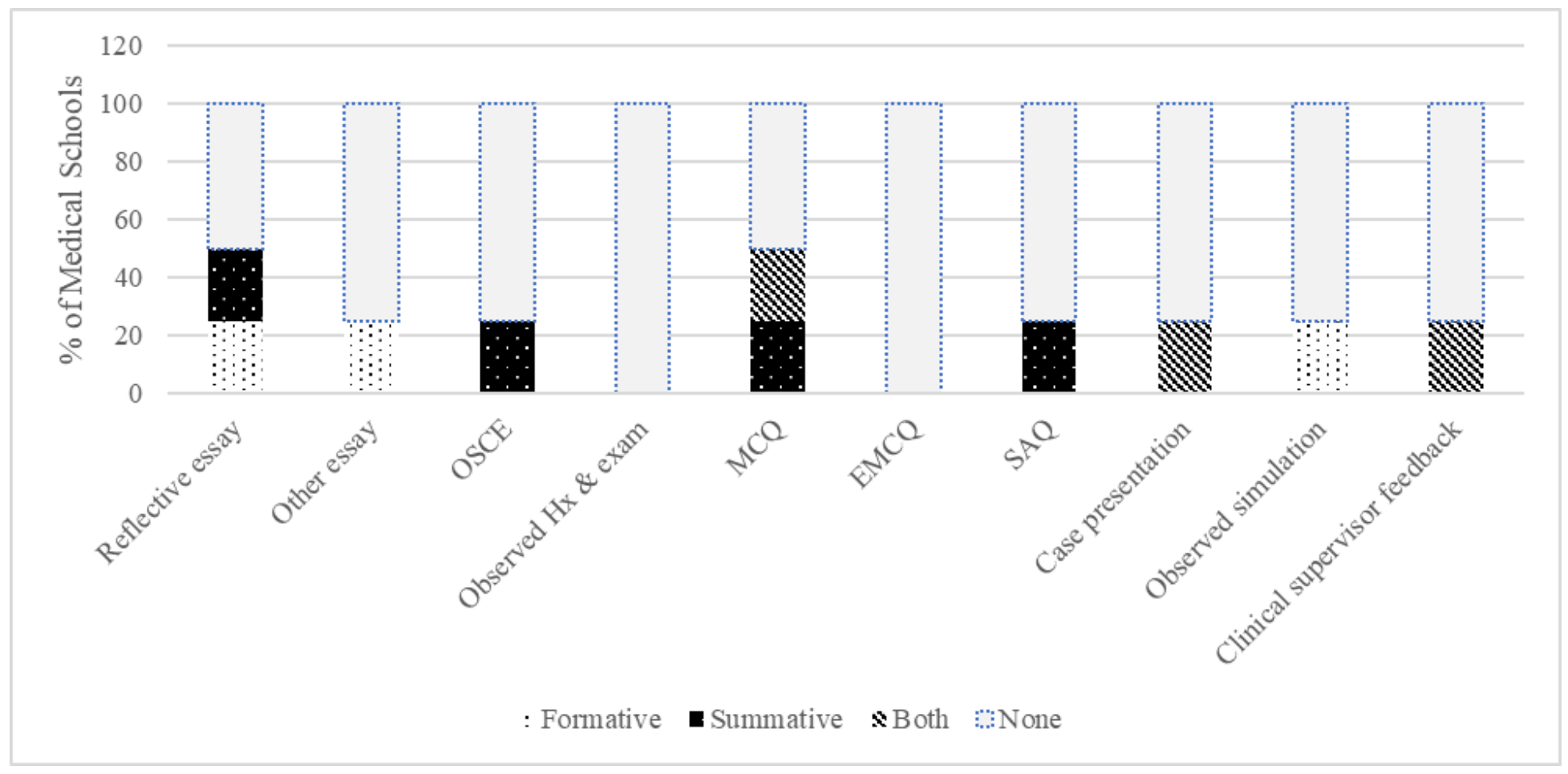

\section{Barriers to development}

The main barriers to development included pressure on curriculum time, lack of clinical attachments in palliative care, lack of assessment and lack of teaching staff. A further issue identified by one convener was a lack of time which limited capacity to develop their teaching. No conveners reported a lack of leadership or support for PEOLC teaching. All felt their colleagues were enthusiastic about PEOLC teaching, which indicates a good level of faculty support, despite these barriers.

\section{Discussion}

This article reports the findings of the first national survey of formal undergraduate teaching in PEOLC in NZ medical schools. Both medical schools show enthusiasm and commitment towards developing this teaching, which is reflected in the development of the national undergraduate PEOLC curriculum and implementation framework. However, there are barriers that restrict what can be achieved without further investment and prioritisation.

The European Association of Palliative Care (EAPC) EDUPALL undergraduate palliative medicine curriculum recommends 72 hours of formal PEOLC teaching [31]. Despite recent progress, there is still a long way to go before this target is met within New Zealand medical schools. While adding new content to an overcrowded course is challenging, the curriculum must reflect national health priorities, which include PEOLC [27].

The EAPC recommends that teaching be structured with short priming sessions in the early stages of training, followed by dedicated block teaching in the clinical years to ensure clarity of key PEOLC 
concepts [31]. On the other hand, integrating content into existing courses creates opportunities for interdepartmental collaboration without over-stretching the curriculum and reflects the integrated, multidisciplinary nature of palliative care. However, integration may come at a cost to visibility unless clear links with related learning are made. Outcomes and objectives must be clearly defined and assessed with vertical and horizontal integration and a combination of dedicated block teaching of core concepts and co-facilitated teaching with other disciplines e.g. Oncology. Teaching should reflect the values of empathy, compassion, respect, Te Whare Tapa Whā (holistic care) and multidisciplinary teamwork and supported by supervised clinical contact with palliative care patients, families and healthcare providers. Online learning platforms can serve as a helpful repository for learning activities and resources for independent inquiry. Web-based resources such as PCC4U (pcc4u.org.au), e-ELCA (Learning Path for Medical Students) (https://www.e-lfh.org.uk) provide consistent learning messages and optimise face to face discussion using a flipped classroom approach. Resources for the healthcare workforce, such as End of Life Essentials (https://www.endoflifeessentials.com.au) could also be adapted (with permission) for undergraduate teaching. Nurturing enthusiasm for PEOLC through student-led special interest groups using expert clinicians as visiting speakers to inspire the next generation of palliative medicine physicians is another worthwhile investment.

Assessment is an essential component of any curriculum and more formal assessment of students' knowledge, skills and attitudes towards PEOLC is required at all levels of the curriculum. A variety of assessment tools, including reflective reports, should be aligned with relevant teaching and learning experiences, especially when students interact with people who have PEOLC needs. Given the collaborative relationship between medical schools, assessments may be shared and the results used to provide useful data to inform further development.

Without supervised interactions with people who have PEOLC needs, many junior doctors will qualify without having achieved basic clinical competencies in PEOLC. Clinical contact with specialist palliative care providers is limited by service capacity, so more creative ways of providing this experience must be identified. Recommendations include longitudinal cases where students follow a patient and their whānau (family) over time, attend specialist appointments and visit the person at home, hospice or hospital. However, people with PEOLC needs exist in all healthcare settings, so there is ample opportunity to learn about primary palliative care as long as students are well prepared and supervised. Ongoing education for clinical staff is therefore required to raise awareness and understanding about PEOLC, out of which palliative care 'champions' may emerge to help facilitate student learning.

There are some limitations to this research. The survey was not a formal audit of PEOLC teaching in MBChB programmes but was based on subjective reporting from module conveners. While they are best placed to comment on the curriculum, they may have over or under-estimated the teaching and clinical learning opportunities they provide. Because PEOLC is integrated throughout the curriculum it may be difficult to quantify in a complex course where this subject could be addressed in several different areas. Similarly, exposure to people with PEOLC needs in non-specialist palliative care areas occurs opportunistically, so cannot be quantified. Further research is required to investigate any association 
between undergraduate education and graduates' self-efficacy and attitudes towards caring for people near the end of life.

\section{Conclusions}

The aging population combined with increasing prevalence of people with multimorbidities and associated complexity is placing extra pressure on health services in New Zealand and creating more demand for palliative care. Significant progress has been made towards developing undergraduate education in PEOLC in New Zealand medical schools. However, further investment and prioritisation is needed to support ongoing development to ensure graduates have the knowledge, skills and attitudes they need to provide safe, effective and compassionate care for patients and whānau (family) who are nearing the end of life, and to meet the needs of the population into the future.

\section{Abbreviations}

PEOLC

palliative and end of life care

NZ

New Zealand

\section{Declarations}

\section{Ethics Approval and consent to participate:}

This research was conducted with the full approval of the University of Otago Human Ethics Committee ref \#: 19/009. Informed consent was provided electronically by all participants prior to participating in the survey.

\section{Consent for publication}

Consent for publication was received from all participants prior to participating in the survey

\section{Availability of data and materials}

All data generated or analysed during this study are included in this published article.

\section{Competing interests}

The authors declare they have no competing interests.

\section{Funding}

This research was supported by a University of Otago Doctorate in Medical Education Scholarship. 
Authors contributions

LH designed and distributed the survey, collected the data, analysed the results and wrote the manuscript. El assisted with statistical analysis and RE, El, JR, RW and RD supervised the project, read, edited and approved the final manuscript.

All methods were carried out in accordance with the relevant guidelines and regulations.

The Aotearoa New Zealand Undergraduate Medicine Palliative and End of Life Care Working Group

\section{References}

1. Ministry of Health: Review of Adult Palliative Care Services in New Zealand. In. Wellington: Ministry of Health; 2017a.

2. Gott M, Frey R, Raphael D, O'Callaghan A, Robinson J, Boyd M: Palliative care need and management in the acute hospital setting: a census of one New Zealand hospital. BMC Palliative Care 2013, 12(1):15.

3. Barclay S, Whyte R, Thiemann P, Benson J, Wood DF, Parker RA, Quince T: An important but stressful part of their future work: medical students' attitudes to palliative care throughout their course. $J$ Pain Symptom Manage 2015, 49(2):231-242.

4. Palliative Care [https://www.who.int/news-room/fact-sheets/detail/palliative-care]

5. Latta L, MacLeod R: Palliative Care Education: An Overview. In: Textook of Palliative Care. edn. Edited by MacLeod R, Van den Block L: Springer, Cham; 2018: 1-21.

6. Gibbins J, McCoubrie R, Forbes K: Why are newly qualified doctors unprepared to care for patients at the end of life? Med Educ 2011, 45(4):389-399.

7. Smith-Han K, Martyn H, Barrett A, Nicholson H: "That's not what you expect to do as a doctor, you know, you don't expect your patients to die." Death as a learning experience for undergraduate medical students. BMC Medical Education 2016, 16(1):108.

8. Kelly E, Nisker J: Medical students' first clinical experiences of death. Med Educ 2010, 44.

9. Lloyd-Williams M, MacLeod RD: A systematic review of teaching and learning in palliative care within the medical undergraduate curriculum. Medical teacher 2004, 26(8):683-690.

10. Peters L, Cant R, Payne S, O'Connor M, McDermott F, Hood K, Morphet J, Shimoinaba K: How Death Anxiety Impacts Nurses' Caring for Patients at the End of Life: A Review of Literature. The Open Nursing Journal 2013, 7:14-21.

11. Searles McClatchey I, King, S.: The impact of death education on fear of death and death anxiety among human services students. OMEGA-Journal of death and dying 2015, 71(4):343-361.

12. Barrere C, Durkin A, LaCoursiere S: The Influence of End-of-Life Education on Attitudes of Nursing Students. International Journal of Education Scholarship 2008, 5(1 Article 11):18. 
13. World Health Assembly: Strengthening of palliative care as a omponent of comprehensive care throughout the life course. In.; 2014.

14. McMahon D, Wee, B.: Medical undergraduate palliative care education (UPCE). BMJ supportive \& palliative care $2019,0: 1-3$.

15. Horowitz R, Gramling R, Quill T: Palliative care education in US medical schools. Medical education 2014, 48(1):59-66.

16. Fitzpatrick D, Heah R, Patten S, Ward H: Palliative Care in Undergraduate Medical Education-How Far Have We Come? American Journal of Hospice and Palliative Medicine ${ }^{\circledR}$ 2017, 34(8):762-773.

17. Arias-Casais N, Garralda E, Rhee JY, de Lima L, Pons JJ, Clark D, Hasselaar J, Ling J, Mosoiu D, Centeno C: EAPC Atlas of Palliative Care in Europe 2019: Vilvoorde: EAPC Press; 2019.

18. Walker S, Gibbins J, Barclay S, Adams A, Paes P, Chandratilake M, Gishen F, Lodge P, Wee B: Progress and divergence in palliative care education for medical students: A comparative survey of UK course structure, content, delivery, contact with patients and assessment of learning. Palliative Medicine 2016, 30(9):1-9.

19. Carrasco JM, Lynch TJ, Garralda E, Woitha K, Elsner F, Filbet M, Ellershaw JE, Clark D, Centeno C: Palliative Care Medical Education in European Universities: A Descriptive Study and Numerical Scoring System Proposal for Assessing Educational Development. J Pain Symptom Manage 2015, 50(4):516-523 e512.

20. Walker S, Gibbins J, Paes P, Adams A, Chandratilake M, Gishen F, Lodge P, Wee B, Barclay S: Palliative care education for medical students: Differences in course evolution, organisation, evaluation and funding: A survey of all UK medical schools. Palliative Medicine 2016.

21. DeCoste-Lopez J, Madhok J, Harman S: Curricular innovations for medical students in palliative and end-of-life care: a systematic review and assessment of study quality. J Palliat Med 2015, 18(4):338-349.

22. Head BA, Schapmire TJ, Earnshaw L, Chenault J, Pfeifer M, Sawning S, Shaw MA: Improving medical graduates' training in palliative care: advancing education and practice. Adv Med Educ Pract 2016, 7:99-113.

23. Centeno C, Ballesteros M, Carrasco JM, Arantzamendi M: Does palliative care education matter the medical students? The experience of attending an undergraduate course in palliative care. $B M J$ supportive \& palliative care 2014, 6(1):1-7.

24. Noguera A, Robledano R, Garralda E: Palliative care teaching shapes medical undergraduate students' professional development: a scoping review. Current Opinion Supportive \& Palliative Care 2018, 12(4):495-503.

25. The Economist Intelligence Unit: The 2015 Quality of Death Index: Ranking palliative care across the world. In. London, UK; 2015.

26. Ministry of Health: Te Ara Whakapiri: Principles and guidance for the last days of life. In., 2nd edn. Wellington: Ministry of Health; 2017.

27. Ministry of Health: Palliative Care Action Plan. In. Wellington; 2017b. 
28. McKimm J, Wilkinson T, Poole P, Bagg W: The current state of undergraduate medical education in New Zealand. Medical teacher 2010, 32:456-460.

29. Medical Council of New Zealand: Good Medical Practice. In.: Medical Council of New Zealand; 2016.

30. Field D, Wee, B.: Preparation for palliative care: teaching about death, dying and bereavement in UK medical schools 2000-2001. Medical education 2002, 36(6):561-567.

31. Mason S, Ling J, Stanciulescu L, Payne C, Paal P, Albu S, Noguera A, Boeriu E, Poroch V, Elsner F et al: From European Association for Palliative Care Recommendations to a Blended, Standradized, Freeto-Access Undergraduate Curriculum in Palliative Medicine: The EDUPALL Project. Journal of Palliative Medicine 2020, 23(12):1571-1585. 